\title{
COVID-19 mass vaccination campaign for healthcare workers in a low-resource setting: A clinician-driven initiative
}

\author{
D L Reddy, ${ }^{1}$ MB ChB, MMed, FCP (SA), Cert ID (SA) Phys; Z Dangor, ${ }^{2}$ MB BCh, MMed, FC Paed (SA), Cert Pulmonology (SA) Paed, PhD; \\ N Lala, ${ }^{2}$ MB BCh, MMed, FC Paed (SA), Cert Nephrology (SA) Paed; J Johnstone, ${ }^{1}$ National Certificate in Administration; \\ L Maswabi, ${ }^{3}$ BPharm Hons, MMENVC; J M L Tsitsi, ${ }^{1}$ MB BCh, FCP (SA)

\begin{abstract}
${ }^{1}$ Department of Internal Medicine, School of Clinical Medicine, Faculty of Health Sciences, University of the Witwatersrand, Johannesburg, South Africa

${ }^{2}$ Department of Paediatrics, School of Clinical Medicine, Faculty of Health Sciences, University of the Witwatersrand, Johannesburg, South Africa

${ }^{3}$ Pharmaceutical Services, Chris Hani Baragwanath Academic Hospital, Johannesburg, South Africa
\end{abstract}

Corresponding author: Z Dangor (ziyaad.dangor@wits.ac.za)

\begin{abstract}
COVID-19 vaccination has been globally accepted as a critical public health response measure to prevent severe disease and death, alleviate strain on healthcare systems, and prevent onward transmission of SARS-CoV-2. The South African Department of Health's plan to vaccinate 1.25 million healthcare workers through the Sisonke Early Access Vaccine Rollout for Healthcare Workers presented both opportunities and challenges in terms of designing and implementing a mass vaccination roll-out in the resource-limited state sector. We present our experiences and challenges from the largest hospital in Africa, and hope that this will assist other institutions with planning successful COVID-19 mass vaccination campaigns.
\end{abstract}

S Afr Med J 2021;111(7):610-614. https://doi.org/10.7196/SAMJ.2021.v111i7.15712

On 31 December 2019, the World Health Organization reported the emergence of an outbreak of pneumonia cases in Wuhan, China. The disease was later termed coronavirus disease 2019 (COVID-19) and the causative agent was identified as a novel coronavirus, SARS-CoV-2. ${ }^{[1]}$ The first case of COVID-19 in South Africa (SA) was announced on 5 March 2020, and a cumulative total of $\sim 1.5$ million confirmed cases and 50000 deaths had been recorded by 7 March 2021. ${ }^{[2,3]}$ The COVID-19 vaccination roll-out for healthcare workers (phase 1) was planned for February 2021 using the Oxford AstraZeneca vaccine. ${ }^{[4,5]}$ However, concerns arose about the efficacy of COVID-19 vaccine candidates in the context of dominance of the B.1.351 variant, as it contained mutations at the receptor-binding domain of the virus, the target site of many vaccines. ${ }^{[6,7]}$ Further data analysis revealed that a two-dose regimen of the AstraZeneca ChAdOx1 nCoV-19 vaccine had an efficacy of $10.4 \%$ against mild to moderate COVID-19 caused by the B.1.351 variant ${ }^{[8]}$ In contrast, interim analysis of the single-dose Johnson \& Johnson/Janssen Ad26.COV2.S vaccine (J\&J) demonstrated $57 \%$ protection against the B.1.351 lineage of SARS-CoV-2 and complete protection against COVID-19 hospitalisation and death. ${ }^{[9]}$ These findings led to a public announcement on 7 February 2021 that healthcare workers would be vaccinated through an implementation study using the J\&J vaccine, under the name Sisonke Early Access Vaccine Rollout for Healthcare Workers. ${ }^{[10,11]}$

A core vaccine team was formed at Chris Hani Baragwanath Academic Hospital (CHBAH) on 13 January 2021. CHBAH is the largest hospital in the southern hemisphere and the third-largest in the world, with a bed capacity of 3200 beds and a staff complement of $7400{ }^{[12]}$ The facility is located in Soweto, a peri-urban town $27 \mathrm{~km}$ south-west of Johannesburg in the most populous province of the country, Gauteng. ${ }^{[12]}$ The hospital serves a population of
$>1.3$ million people, and offers a full range of generalised specialist and subspecialist services. ${ }^{[12]}$

The vaccine team planned for a 'mass vaccination' roll-out of staff on the launch date, 17 February 2021. Mass vaccination strategies are considered to be most useful in pandemic situations, as they allow for the fast and efficient vaccination of a large number of susceptible people, using a central vaccination site. ${ }^{[13]}$ The benefits of mass vaccination of healthcare worker programmes over ward-toward-based vaccination programmes are: $(i)$ a streamlined process for pharmacy vaccine delivery, preparation and secure storage, while also ensuring that the cold chain is maintained; (ii) easy access to an emergency care team that remains in the vaccination site in the event of adverse events following immunisation (AEFIs); and (iii) a centrally controlled data capture system. Disadvantages include the need for a large number of staff to support the mass vaccination process itself, requiring precision and careful planning. ${ }^{[14,15]}$ There is a paucity of peer-reviewed literature on the implementation of mass vaccination programmes, particularly in low-resource, lowtechnology settings. ${ }^{[16-18]}$

\section{Logistical concerns of the mass vaccination campaign}

The core team began by meeting with various key stakeholders such as pharmacy management, the Sisonke study investigators, occupational health and safety (OHS) and labour unions. Major work streams and tasks were identified (Table 1). In addition, a large number of staff was required (Table 2). The majority of the staff who volunteered to support the vaccine roll-out were clinicians: doctors of all ranks, nurses of all ranks, psychologists, physiotherapists, and occupational and speech therapists. 
Table 1. Work stream planning for Chris Hani Baragwanath Academic Hospital mass vaccination campaign

\begin{tabular}{|c|c|c|}
\hline Work streams & Stream leaders & Tasks \\
\hline Staff education to build vaccine confidence & Public relations officer & $\begin{array}{l}\text { - Information pamphlets printed and distributed at staff entrances } \\
\text { - 'Town hall' online meetings } \\
\text { - Staff education via social media (e.g. Facebook) } \\
\text { - Targeted onsite information sessions }\end{array}$ \\
\hline Categorisation of staff and databases & $\begin{array}{l}\text { Line managers and } \\
\text { administrators }\end{array}$ & $\begin{array}{l}\text { - Categorisation of staff according to risk priority groups } \\
\text { - Pre-registration for willingness to vaccinate (electronic form) } \\
\text { - Schedule vaccination appointments and compile registration lists }\end{array}$ \\
\hline Pharmacy preparation and monitoring & Pharmacy manager & $\begin{array}{l}\text { - Standard operating procedure for vaccine handling and transfer } \\
\text { - Ensure cold chain - access to fridge and cooler boxes } \\
\text { - Security of vaccine vials }\end{array}$ \\
\hline Vaccinator identification and training & Vaccinator team leader & - Vaccinator identification and training \\
\hline Emergency medical team for AEFIs & Emergency team leader & $\begin{array}{l}\text { - Resuscitation trolley and emergency drugs } \\
\text { - Transport (stretchers, wheelchairs and ambulance services) }\end{array}$ \\
\hline OHS & OHS team leader & $\begin{array}{l}\text { - Have mechanisms for reporting AEFIs } \\
\text { - Medical support for staff with delayed adverse events } \\
\text { - Ensure adequate supply of consumables (e.g. cotton swabs) }\end{array}$ \\
\hline Vaccination site and VOC & VOC team & \\
\hline Meeting and co-ordination & & $\begin{array}{l}\text { - Regular site meetings with teams } \\
\text { - Troubleshooting problems }\end{array}$ \\
\hline Site layout and mapping & & - Site map and layout \\
\hline Equipment & & - Vaccinator stations (desk and chairs) \\
\hline Staffing the site & & - Vaccinators and support staff allocation and shifts \\
\hline Disaster management and evacuation & & $\begin{array}{l}\text { - Emergency exits and evacuation routes } \\
\text { - Fire marshal and extinguishers }\end{array}$ \\
\hline Cleaning and waste management & & $\begin{array}{l}\text { - Waste management and sharps disposal } \\
\text { - Personal protective equipment } \\
\text { - Sanitising station and surfaces } \\
\text { - Deep clean at start and end of session }\end{array}$ \\
\hline Security and ushering & & - Zoning and unidirectional flow \\
\hline
\end{tabular}

We identified a large, well-ventilated hall as the most suitable vaccination site, and formed a venue operation centre team to assist with the set-up and infrastructure of the vaccination site. Additional needs were a large outdoor tent to serve as a waiting area; procuring furniture and equipment for the vaccination site; demarcating spaces for parking, assembly, a waiting area, a vaccination area and an observation area; the provision of computers and connectivity for data capturing; and a reliable power supply with a back-up generator (Fig. 1).

\section{The vaccine roll-out process}

Our preparation for mass vaccination at $\mathrm{CHBAH}$ involved creation of a staff database from human resources, line managers, and self-completed electronic registration forms. Using this database, vaccination appointments were scheduled by email or text messages. Staff had the opportunity to reschedule their appointments based on availability. The preregistration booking system was intended to minimise time spent away from the staff working areas and the impact on service delivery, and to allow for social distancing.

Our vaccinators were drawn from a pool of nurses who were trained and accredited using the national COVID-19 Vaccination Training for Healthcare Workers online course by the nursing education team at $\mathrm{CHBAH}$. The training included infection prevention and control measures on appropriate personal protective equipment to be worn, and sanitisation of their individual vaccination stations. To allow for social distancing while optimising efficiency, the vaccinator stations were arranged into four rows $(\mathrm{A}, \mathrm{B}, \mathrm{C}, \mathrm{D})$, each comprising six vaccinator stations (A1 - 6, B1 - 6, C1 - 6, D1 - 6), which allowed for 24 vaccinator stations in total (Fig. 2). Distribution of vaccine doses to the vaccinators was co-ordinated by pharmacy teams and OHS nurses prior to the vaccinees entering the vaccination hall. The pharmacy and OHS teams were also responsible for the reconciliation of all vaccine doses dispensed after each round of 24 vaccinees.

The vaccination process, as depicted in Fig. 2, involved:

- Scheduled vaccinees arrived at the vaccination site with a form of identification and proof of booking.

- Vaccinees were directed to the registration tent, where they were screened for COVID symptoms, and gave consent for vaccination.

- Vaccinees were then asked to seat themselves in the waiting area.

- Any extra paperwork was completed and information on the process was provided to the vaccinees by a co-ordinator.

- Vaccinees were directed into the vaccination hall in groups of 24 at a time ( 24 vaccination stations accommodated by 24 vaccinees in each round).

- Vaccinees were asked to leave the hall after vaccination, to be observed for 15 minutes in the observation area.

- Any vaccinee who was unwell was immediately taken to the emergency medicine team, who were stationed behind screens on the side of the vaccination hall (Fig. 2).

This process continued throughout the day, with tea and lunch breaks for vaccinators and co-ordinators coinciding with times needed for 


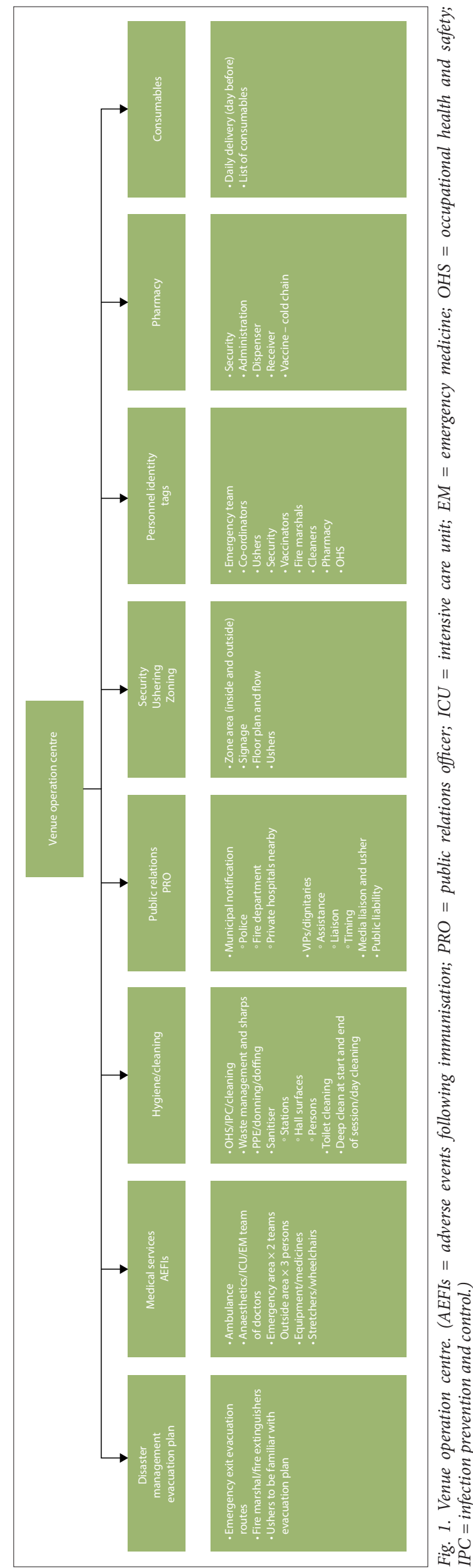

the pharmacy to replenish vaccine stock. Multiple co-ordinators $(n=14)$ were required in our mass vaccination roll-out, and this contributed to the overall organisation, precision and teamwork that led to a successful campaign (Table 2). Our process emphasised the importance of piloting the programme on day 1 , troubleshooting and adapting at the end of each day. We were able to vaccinate 5659 staff by the end of our 8 -day vaccination campaign, with 32 vaccinated on day 1 , and gradually upscaling to 1160 vaccinated on day 8 (Table 3 ).

\section{Pitfalls and unique challenges}

Initial pitfalls identified in our mass vaccination planning included:

- An objective method for categorisation of staff according to their risk of acquiring severe COVID-19 disease was lacking: we couldn't guarantee that all staff at highest risk would be vaccinated first.

- An effective booking system taking into account staff availability was lacking, owing to the scale of administrative support needed.

- Reliance on clinicians to staff the vaccination site without providing back-up clinical support or de-escalation of clinical services during the roll-out period. Clinician-led services are widely lauded for their success; however, when this process is employed, it should be a dedicated responsibility and should not compromise patient care. ${ }^{[19]}$

- The urgency of the roll-out and the change from the AstraZeneca to the J\&J vaccine. This process resulted in new stakeholders, the need to implement a national electronic booking system, and a limited daily supply of vaccine doses.

- Our team was additionally tasked with assisting other frontline private and public sector healthcare workers, which was not initially planned for.

- External factors such as visits by dignitaries and media to the vaccine site.

\section{Lessons learned from a mass vaccination campaign}

- Choose a vaccination site on the basis of good ventilation, space, lighting, toilets and shelter for poor weather conditions. Ensure unidirectional flow of vaccinees through the site, with adequate space in an observation area.

- Find a team of passionate, motivated individuals. Ensure that vaccinators are trained, supported and rested. Donations of refreshments went a long way to boost morale.

- Pharmacy teams need training on storage and preparation of the vaccine.

- Strengthen the OHS team, as they are needed to drive the vaccination process and 'mop up' afterwards. OHS must prepare for AEFIs at a dedicated OHS vaccination clinic.

- Communication between all stakeholders is essential, especially on vaccination days: have clear channels of communication between the site vaccination team and the pharmacy.

- Ensure fast and reliable internet connectivity, as well as electricity and a back-up generator. Ideally have a pre-registration booking system and a back-up list for each day to avoid wastage of vaccine doses. Generate 'batches' of vaccinees as per risk categorisation, and provide vaccine appointments timeously.

- Encourage visible involvement from hospital management - this adds credibility and confidence to the vaccine campaign.

- Conduct a 'dry-run' or simulation of the vaccination process before starting the roll-out.

- Pilot the process on day 1 before scaling up: prepare to change the plan as it unfolds, taking into account the demands and pressure from other stakeholders.

\section{Conclusions}

The mass vaccination strategy developed and implemented at $\mathrm{CHBAH}$ was targeted at healthcare workers. Since the launch, our strategy has been adapted for use by other public and private institutions in SA. With 
Table 2. Staff requirements at vaccination site per day

\begin{tabular}{|c|c|c|}
\hline Category & Function & Number needed at vaccination site \\
\hline Vaccinators & $\begin{array}{l}\text { Administer vaccinations to vaccinees, completion of forms and } \\
\text { vaccine cards } \\
\text { Online EVDS data capture if possible }\end{array}$ & $\begin{array}{l}24 \text { ( } 4 \text { rows with } 6 \text { vaccinators per } \\
\text { row) }\end{array}$ \\
\hline OHS nurses & $\begin{array}{l}\text { Assist with distribution of vaccines doses to vaccinator stations, } \\
\text { collection of completed vaccination forms }\end{array}$ & 4 \\
\hline Emergency/ICU team & Emergency services as required & 2 doctors +1 nurse \\
\hline Data capturers & Capture of the vaccination form information into the EVDS system & 5 \\
\hline Pharmacists & $\begin{array}{l}\text { Monitoring of vaccinations, checking of stock, ensuring compliance } \\
\text { with cold chain }\end{array}$ & 2 \\
\hline Site co-ordinator & $\begin{array}{l}\text { Overseeing all components of the vaccination site, different stations } \\
\text { and primary point of contact }\end{array}$ & 1 \\
\hline Information station co-ordinators & $\begin{array}{l}\text { Greeting potential vaccinees, confirming identification and booking } \\
\text { documents }\end{array}$ & 3 \\
\hline EVDS station co-ordinators & Overseeing the EVDS data system and data capturing & $1+4$ personnel \\
\hline Registration co-ordinators & $\begin{array}{l}\text { Oversight of registration process, confirming booking on } \\
\text { registration list, COVID-19 symptom screening and signature for } \\
\text { consent }\end{array}$ & $1+8$ personnel \\
\hline Waiting area co-ordinators & $\begin{array}{l}\text { Oversight of assembly into waiting area and assisting with } \\
\text { completion of any paperwork }\end{array}$ & $1+2$ ushers \\
\hline Foyer co-ordinators & Guiding movement of vaccinees into vaccination hall & $1+2$ ushers \\
\hline Hall co-ordinator & $\begin{array}{l}\text { Ensures the smooth operations of the vaccination hall, instructs } \\
\text { rows to be marshaled in and out } \\
\text { Co-ordinates movement of vaccinees into the hall }\end{array}$ & 1 \\
\hline Row co-ordinators & $\begin{array}{l}\text { Assists OHS with distribution of syringes, ensures completion } \\
\text { of vaccinator forms, troubleshoots problems within row, ensures } \\
\text { functionality of row }\end{array}$ & 4 \\
\hline Observation co-ordinators & $\begin{array}{l}\text { Oversight of exit from vaccination hall into observation area, } \\
\text { observes vaccinees for any adverse effects and instructs on } \\
\text { appropriate next steps }\end{array}$ & 1 doctor +2 nurses \\
\hline
\end{tabular}
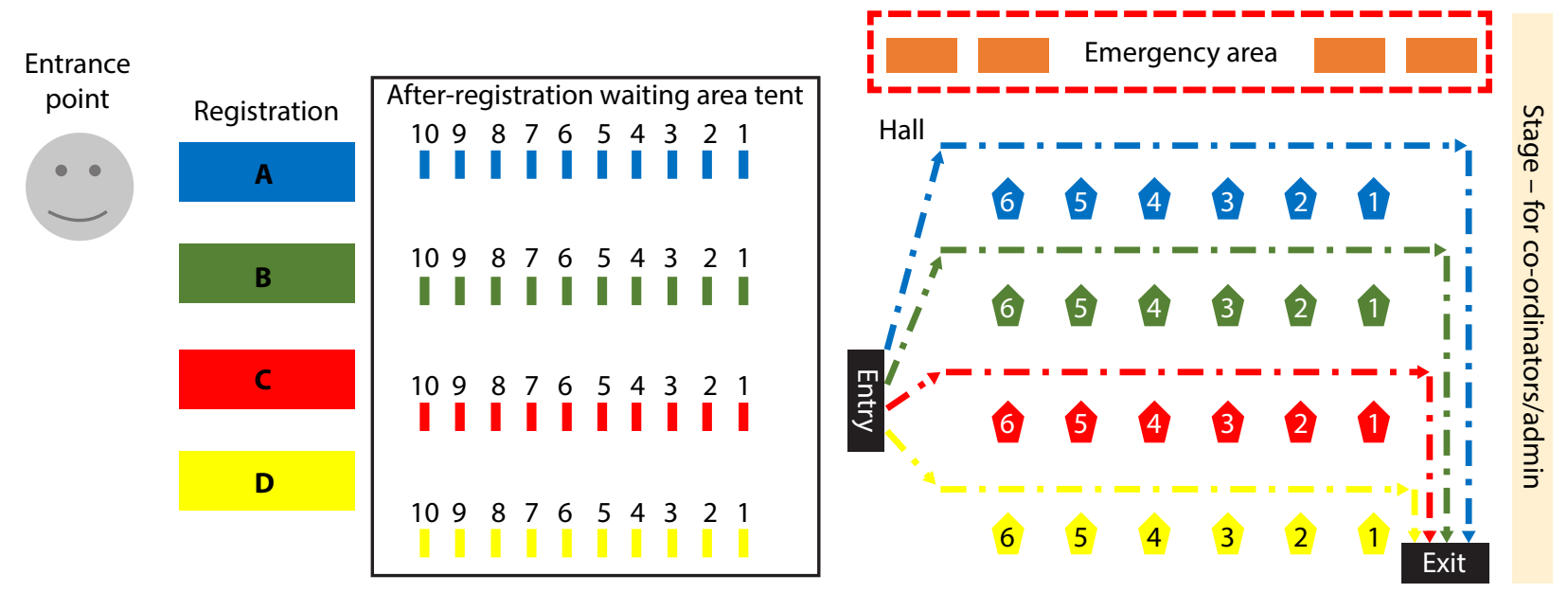
Veranda area for 15-minute post-vaccination screening

Fig, 2. Vaccination process at Chris Hani Baragwanath Academic Hospital. 
Table 3. Numbers of vaccine doses administered at Chris Hani Baragwanath Academic Hospital during mass vaccination roll-out to healthcare workers

\begin{tabular}{ll}
\hline Date & Number of vaccine doses administered \\
\hline 17 February 2021, Gauteng launch of Sisonke roll-out & 32 \\
18 February & 240 \\
19 February & 460 \\
22 February & 788 \\
23 February & 823 \\
24 February & 1018 \\
25 February & 1138 \\
26 February & 1160
\end{tabular}

a committed core lead team, including pharmacists and clinicians, support from managers and a suitable venue, mass vaccination campaigns can be successfully rolled out in resource-limited settings. Innovation, adaptability and teamwork are critical.

\section{Declaration. None.}

Acknowledgements. The authors wish to acknowledge members of the CHBAH COVID-19 Vaccine Committee. Management: Dr Nkele Lesia, Dr Nita Soma; Human resources/admin: Mr Vollie Adoons, Mr Nkosiyethu Mazibuko and team; Occupational health: Ms Chama Jere, Ms Patience Seletela, Ms Refilwe Legoale, Ms Mariam Nephawe, Ms Prisca Ngwenya, Dr Tumelo Makamu; Pharmacy: Mr Saul Dikgang, Mrs Azraa Paruk, Mrs Tshilidzi Shabangu, Ms Courtney Jacobs; Nursing: Mr Baldwin Mulaudzi, Mrs Tshidi Tlhapi, Mrs Ralinala, Mrs Ngeno, Mrs Ntikane, Mrs Sarah Magodielo and the team of vaccinators; Infection prevention and control: Dr Hermenegilda Madeira, Mrs Letta Mafoko, Mrs Kefilwe Tladi; Environmental health: Mrs Nangani Ramulongo and team; Allied medical disciplines: Mrs Premila Naik, Dr Sadna Balton and team; Logistics: Mr Kgadimane, Mr Leon van der Westhuizen and team; Equipment: Mrs Tlale and team; Security: Mr Lucky Mnisi, Mr Ngubane and team; Risks24 ThreeSixtyFive Security: Mr Hoosein Loonat; Clinicians: Dr Kavita Makan, Dr Denishan Govender, Prof. Michelle Wong, Dr Waunita Naidoo, Dr Palesa Mogane, Dr Anisah Mamoojee, Prof. Martin Smith, Dr Zafar Khan, Prof. Sithembiso Velaphi, Prof. David Moore, Dr Nosisa Sipambo, Dr Charl Verwey, Prof. Yasmin Adam, Dr Jayshree Jeebodh, Dr Mary Adam, Dr Vuyelwa Baba, Prof. Rudo Mativha, Dr Kuban Naidoo, Dr Jacqui Brown, Dr Tristan Pillay, Dr Roland Hollhumer, Dr Hassan Alli, Dr Tamarin Nell, Dr Foriwah Obeng-Adjei, Prof. Yasmien Jeenah, Dr Sanushka Moodley, Dr Alex Maisto, Dr Faeeza Nawab, Dr Wendy Friedlander, Dr Nathalie de Klerk, Dr Lisa Galvin, Dr Yumna Minty, Dr Sibu Zuma, Dr Sheila Lutaaya, Mrs Jasmin Kooverjee, Ms Ashleigh Craig, Ms Tasneem Bulbulia, Mr Ahmed Mayet; Ms Tatiana Campbell; Sisonke working team: Prof. Glenda Gray, Prof. Ameena Goga, Ms Fatima Mayat, Dr Erica Lazarus, Ms Anusha Nana, Mr Nazim Akoojee and the pharmacy team.

Author contributions. DLR and ZD compiled the manuscript. NL, JJ, LM and JMLT contributed to the final manuscript. ZD, NL and DLR contributed to the planning and set-up of the infrastructure. LM co-ordinated the pharmaceutical response, and JJ was responsible for administration. JMLT provided oversight and guidance throughout the process.
Funding. None.

Conflicts of interest. None.

1. World Health Organization. Archived: WHO Timeline - COVID-19. https://www.who.int/news item/27-04-2020-who-timeline---covid-19 (accessed 7 March 2021).

2. National Institute for Communicable Diseases. First case of COVID-19 announced - an update. 5 March 2020. https://www.nicd.ac.za/first-case-of-covid-19-announced-an-update/ (accessed 7 March 2021).

3. National Department of Health, South Africa. COVID-19 Coronavirus South African Resource Portal. https://sacoronavirus.co.za/ (accessed 7 March 2021).

4. South African Government. Minister Zweli Mkhize: Update on SARS-CoV-2 Coronavirus vaccine rollout strategy. 7 January 2021. https://www.gov.za/speeches/minister-Zweli-mkhize-update-sarscov-2-coronavirus-vaccine-rollout-strategy-7-jan-2021\# (accessed 7 March 2021).

5. Department of Health, Republic of South Africa. COVID-19 response slide deck. 7 January 2021.

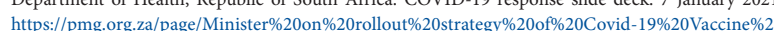
\&\%20status $\% 20$ of $\% 20$ healthcare $\% 20$ services $\% 20$ in $\% 2$ provinces $\% 20$ in $\% 20$ relation $\% 20$ to $\% 20 \mathrm{CO}$ $\& \% 20$ status $\% 20$ of $\% 20$ healthca
VID (accessed 7 March 2021).

6. Tegally $\mathrm{H}$, Wilkinson E, Giovanetti M, et al. Emergence and rapid spread of a new severe acute respiratory syndrome-related coronavirus 2 (SARS-CoV-2) lineage with multiple spike mutations in South Africa. medRxiv 2020 (epub 22 December 2020). https://doi.org/10.1101/2020.12.21.20248640

7. National Department of Health, South Africa. COVID-19 Coronavirus South African Resource Portal. New COVID-19 variant identified in SA. 18 December 2020. https://sacoronavirus. co.za/2020/12/18/new-covid-19-variant-identified-in-sa/ (accessed 7 March 2021).

8. Madhi SA, Baillie V, Cutland CL, et al. Safety and efficacy of the ChAdOx1 nCoV-19 (AZD1222) Covid-19 vaccine against the B.1.351 variant in South Africa. medRxiv 2021 (epub 12 February 2021). https://doi.org/10.1101/2021.02.10.21251247

9. Janssen Biotech, Inc. COVID-19 Vaccine Ad26.COV2.S VAC31518 (JNJ-78436735) Sponsor Briefing Document Vaccines and Related Biological Products Advisory Committee meeting, 26 February 2021. https://www.fda.gov/media/146219/download (accessed 7 March 2021).

10. National Department of Health, South Africa. COVID-19 Coronavirus South African Resource Portal. Media Briefing: Important update on vaccines. 7 February 2021. https://sacoronavirus. co.za/2021/02/07/media-briefing-important-update-on-vaccines/ (accessed 7 March 2021).

11. Daily Maverick. COVID-19 Vaccines Update. South Africa faces serious setbacks in its AstraZeneca vaccination campaign - government turns to Plan B. 7 February 2021. https://www.dailymaverick. co.za/article/2021-02-07-south-africa-faces-serious-setback-in-its-astrazeneca-vaccinationcampaign-government-turns-to-plan-b/ (accessed 7 March 2021).

2. Chris Hani Baragwanath Hospital. General information. https://www.chrishanibaragwanathhospital. co.za/ (accessed 7 March 2021).

13. Asgary A, Najafabadi MM, Karsseboom R, Wu J. A drive-through simulation tool for mass vaccination during COVID-19 pandemic. Healthcare 2020;8(4):469. https://doi.org/10.3390/ healthcare8040469

14. Mills MC, Salisbury D. The challenges of distributing COVID-19 vaccinations. EClinicalMedicine 2021;31:100674. https://doi.org/10.1016/j.eclinm.2020.100674

15. Hosangadi D, Warmbrod KL, Martin EK, et al. Enabling emergency mass vaccination: Innovations in manufacturing and administration during a pandemic. Vaccine 2020;38(26):4167-4169. https:/ doi.org/10.1016/j.vaccine.2020.04.037

16. Sah R, Shrestha S, Mehta R, et al. AZD1222 (Covishield) vaccination for COVID-19: Experiences, challenges, and solutions in Nepal. Travel Med Infect Dis 2021:40:101989. https://doi.org/10.1016/j. tmaid.2021.101989

17. World Health Organization: Framework for decision-making: Implementation of mass vaccination campaigns in the context of COVID-19. https://www.who.int/docs/default-source/coronaviruse/ framework-for-decision-making-implementation-of-mass-vaccination-campaigns-in-the-contextof-covid19-slide-deck.pdf?sfvrsn=438dccc8_2 (accessed 7 March 2021).

18. World Health Organization. Vaccine safety basics: e-learning course. Mass vaccination campaigns World Health Organization. Vaccine safety basics: e-learning course. Mass vaccination campaig
https://vaccine-safety-training.org/mass-vaccination-campaigns.html (accessed 7 March 2021). https://vaccine-safety-training.org/mass-vaccination-campaigns.html (accessed 7 March 2021).
Daly J, Jackson D, Mannix J, Davidson PM, Hutchinson M. The importance of clinical leadership in the hospital setting. J Healthc Leadersh 2014;6:75-83. https://doi.org/10.2147/JHL.S46161 